\title{
Fast Microwave-Assisted Synthesis and Photoluminescence of $\mathrm{CaWO}_{4}$ Nanocrystals
}

\author{
Quanguo Li, Yanhua Shen, and Taohai Li \\ College of Chemistry, Key Lab of Environment Friendly Chemistry and Application of Ministry of Education, \\ Xiangtan University, Xiangtan 411105, China
}

Correspondence should be addressed to Taohai Li; hnlth@xtu.edu.cn

Received 30 May 2013; Accepted 20 September 2013

Academic Editor: Jun Zhang

Copyright (C) 2013 Quanguo Li et al. This is an open access article distributed under the Creative Commons Attribution License, which permits unrestricted use, distribution, and reproduction in any medium, provided the original work is properly cited.

In this work, $\mathrm{CaWO}_{4}$ nanoparticles have been synthesized by microwave-assisted method at a low temperature of $120^{\circ} \mathrm{C}$. The asprepared powders were characterized by X-ray powder diffraction (XRD), transmission electron microscopy (TEM), and Fourier transform infrared spectroscopy (FT-IR). It is found that the reaction time played an important role in the morphology controlling and crystallinity level of $\mathrm{CaWO}_{4}$ crystals. The effects of photoluminescent properties have a great relationship with crystallinity.

\section{Introduction}

In recent years, with the advance of nanoscale materials science and technology, the synthesis of nanoscale materials with unique properties is becoming more and more important for studying the variation of materials' properties with size and morphology [1-5]. Nanomaterials based on the scheelite-type have attracted considerable interest because of their luminescent property approved use in electrooptic applications [6-8]. $\mathrm{SrWO}_{4}, \mathrm{CaWO}_{4}, \mathrm{PbWO}_{4}$, and $\mathrm{BaWO}_{4}$ were considered to be typical oxides structure of scheelitetype. Locating within tetrahedral $\mathrm{O}$-ion cages, $\mathrm{W}$ ions are isolated from each other in the scheelite structure, while $\mathrm{Ca}$, $\mathrm{Ba}, \mathrm{Sr}$, and $\mathrm{Pb}$ ions are surrounded by eight oxygen ions [9].

$\mathrm{CaWO}_{4}$ with a scheelite structure is an important optical material, which has attracted particular interest because of its applications [10] in quantum electronics or scintillators as laser host material $[11,12]$. $\mathrm{CaWO}_{4}$ powders are usually prepared by traditional solid-state reactions which require high temperature and harsh reaction conditions [13]. Recently, $\mathrm{CaWO}_{4}$ nanoparticles have been prepared by various wet chemical methods [14-18], which needs long reaction time, or nonaqueous solvents, such as hydrothermal method, citrate complex method, combustion process, coprecipitation, microwave-hydrothermal methods, polymeric precursor method, and microwave-solvothermal methods [19-22].
Therefore, to synthesize $\mathrm{CaWO}_{4}$ nanoparticles with a mild method (e.g., low temperature and/or quick reaction time) is of significance in both fundamental and applied studies [23].

In this paper, we report the synthesis, crystal structure, and fluorescence property of $\mathrm{CaWO}_{4}$ nanocrystals, which is prepared from the reaction of $\mathrm{CaCl}_{2}$ and $\mathrm{Na}_{2} \mathrm{WO}_{4} \cdot 2 \mathrm{H}_{2} \mathrm{O}$ in the presence of PEG1000 by fast microwave-assisted method. By controlling the different reaction time, the degree of crystallinity of $\mathrm{CaWO}_{4}$ can be controlled. It means that we can obtain $\mathrm{CaWO}_{4}$ with higher crystallinity target structure by adjusting the reaction time, which is important for the preparation of aimed productions in the system of $\mathrm{Ca}-\mathrm{W}-\mathrm{O}$.

\section{Experimental Section}

2.1. Synthesis. $\mathrm{CaCl}_{2}(\mathrm{AR}), \mathrm{Na}_{2} \mathrm{WO}_{4} \cdot 2 \mathrm{H}_{2} \mathrm{O}$ (AR), and PEG1000 (AR) were used as the starting materials, and all of them were of analytical grade without any further purification. $\mathrm{CaWO}_{4}$ nanocrystals were prepared by microwaveassisted method in the absence of any organic additives. In a typical procedure, $0.1093 \mathrm{~g} \mathrm{CaCl}_{2} 0.1003 \mathrm{~g} \mathrm{Na}_{2} \mathrm{WO}_{4} \cdot 2 \mathrm{H}_{2} \mathrm{O}$, and $0.1409 \mathrm{~g}$ PEG1000 were put into quartz tube and dissolved in $10 \mathrm{~mL}$ distilled water, and the mixture was vigorously stirred for $10 \mathrm{~min}$ to ensure that all reagents were dispersed homogeneously. And then put the sealed quartz 


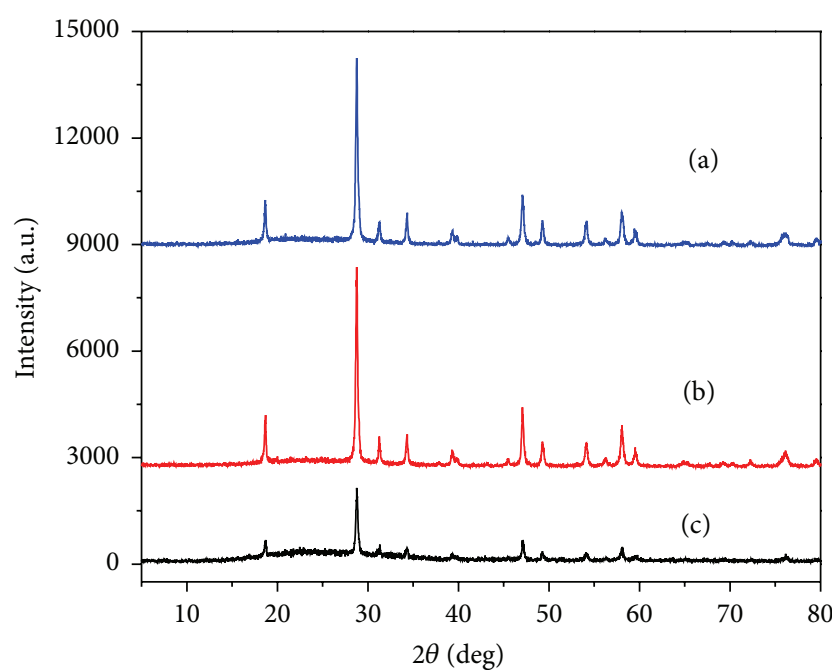

FIGURE 1: XRD patterns of the as-prepared $\mathrm{CaWO}_{4}$ samples synthesized by microwave-assisted method at $120^{\circ} \mathrm{C}$ for different reaction times: (a) $15 \mathrm{~min}$, (b) $10 \mathrm{~min}$, and (c) $5 \mathrm{~min}$, respectively.

tube into the microwave reactor. Reaction temperature and time, pressure, and microwave power output were adjusted according to the parameters of the reactor. After cooling to room temperature naturally, the precipitates were collected, washed with distilled water and absolute ethanol for several times, and then dried in a vacuum oven at about $60^{\circ} \mathrm{C}$ for $24 \mathrm{~h}$.

2.2. Characterization. The morphologies of $\mathrm{CaWO}_{4}$ samples were examined by transmission electron microscopy (TEM) (JEM-2010, JEOL, Japan). The FT-IR spectra (Nicolet-380, Nicolet Instrument Co., USA) were recorded in the region of $4000-400 \mathrm{~cm}^{-1}$. X-ray diffraction (XRD) patterns were measured on a MiniFlex2 goniometer. Employing a scanning rate of $0.02^{\circ} \mathrm{s}^{-1}$ in the $2 \theta$ range from $5^{\circ}$ to $70^{\circ}$, the operating voltage and current were maintained at $30 \mathrm{kV}$ and $15 \mathrm{~mA}$, respectively. Photoluminescence (PL) spectra were recorded by a Hitachi 850 fluorescence spectrometer with a Xe lamp at room temperature. Fourier transform infrared spectroscopic (FT-IR) analysis was carried out using pressed $\mathrm{KBr}$ disks in the region of $4000-400 \mathrm{~cm}^{-1}$ by using a Perkin Elmer spectrometer instrument.

\section{Results and Discussion}

3.1. Structural Analysis. The phase identification of all the products was performed by XRD. To investigate the effect of reaction time on the crystallinity, $\mathrm{CaWO}_{4}$ was prepared with different reaction time. The products synthesized at 120 degrees in $5 \mathrm{~min}, 10 \mathrm{~min}$, and $15 \mathrm{~min}$ show similar patterns, which are in good agreement with the standard values for the tetragonal phase $\mathrm{CaWO}_{4}$ (Fm3hm, JCPDS No. 41-1431). Figure 1 shows the XRD patterns of the products obtained via microwave-assisted method. When reaction time is $5 \mathrm{~min}$, the crystallinity of as-prepared product is considerably low, and there are few peaks that cannot be observed. Therefore,

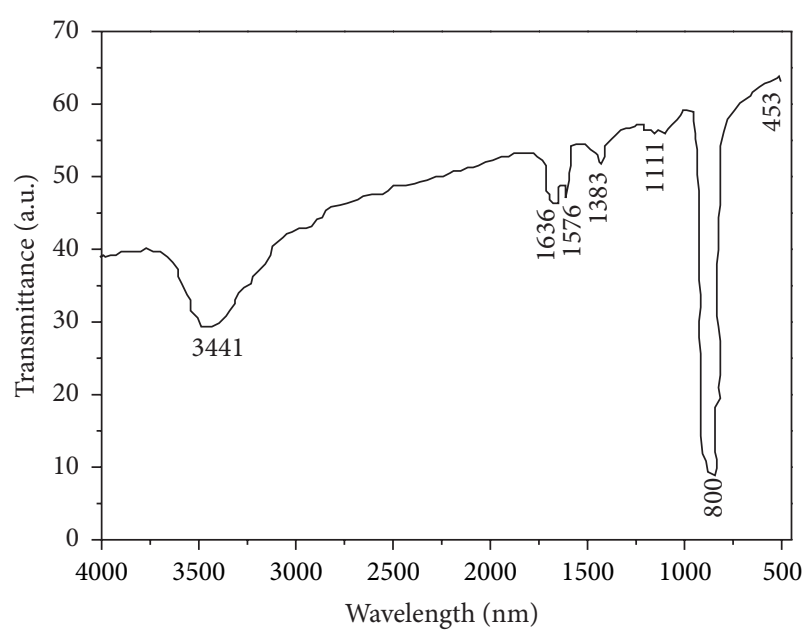

FIgURE 2: The FT-IR spectrum of $\mathrm{CaWO}_{4}$ nanocrystals synthesized under $120^{\circ} \mathrm{C}$, for $15 \mathrm{~min}$.

a longer time supports the formation of the thermodynamically stable, well-crystallized, and uniform products. It is very clear that the crystallinity of obtained products increase with the increasing of reaction time for $15 \mathrm{~min}$ (Figure 1(a)). In a word, the reaction time of the reaction systems was found to play an important role in determining the crystallinity of the $\mathrm{CaWO}_{4}$ nanocrystals.

To further confirm the formation of the $\mathrm{CaWO}_{4}$ crystal structure, Fourier transform infrared (FT-IR) spectroscopy was performed on the as-prepared $\mathrm{CaWO}_{4}$ nanocrystals (Figure 2). The bands at $1383 \mathrm{~cm}^{-1}, 1576 \mathrm{~cm}^{-1}, 1636 \mathrm{~cm}^{-1}$, and $3441 \mathrm{~cm}^{-1}$ are assigned to $\mathrm{O}-\mathrm{H}$ stretching vibration and $\mathrm{H}-$ $\mathrm{O}-\mathrm{H}$ bending vibration [24], respectively. The two bands are the characteristic vibrations of water from air absorbed on the sample surface physically which is completely different from coordinated water in compounds. The $111 \mathrm{~cm}^{-1}$ band is the characteristic vibrations of $\mathrm{CO}_{2}$ in the air. A strong absorption band around $800 \mathrm{~cm}^{-1}$ is related to $\mathrm{O}-\mathrm{W}-\mathrm{O}$ stretches of the $\mathrm{WO}_{4}$ tetrahedron, because the $\mathrm{AWO}_{4}$-type sheelite oxides, having $\mathrm{S} 4$ site symmetry for the $\mathrm{WO}_{4}$ groups, which show the main absorption bands in the region of $400-$ $1000 \mathrm{~cm}^{-1}$, centered around 911, 405, and $833 \mathrm{~cm}^{-1}$ based on the v1, v2, and v3 modes of the WO4 groups, respectively [25]. The $453 \mathrm{~cm}^{-1}$ band is attributed to the $\mathrm{v} 2$ stretching vibration of $\mathrm{W}-\mathrm{O}$ on the same grounds.

3.2. Morphology Control. Figure 3 shows the typical TEM images of $\mathrm{CaWO}_{4}$ samples synthesized via microwaveassisted method at $120^{\circ} \mathrm{C}$ with different reaction time. It is very remarkable that $\mathrm{CaWO}_{4}$ nanocrystals are $63 \mathrm{~nm}$ in diameter, when reaction time is $15 \mathrm{~min}$ (Figure 3(c)). But the diameter of as-prepared $\mathrm{CaWO}_{4}$ is $46 \mathrm{~nm}$ and $62 \mathrm{~nm}$, when reaction time is $5 \mathrm{~min}$ and $10 \mathrm{~min}$ (Figures 3(a) and 3(b)), respectively, which are in good agreement with the XRD results. This result further confirms that longer heating time would promote the crystallization of $\mathrm{CaWO}_{4}$ nanocrystals. Figure 3(c) shows that the spacing of the lattice fringe is 


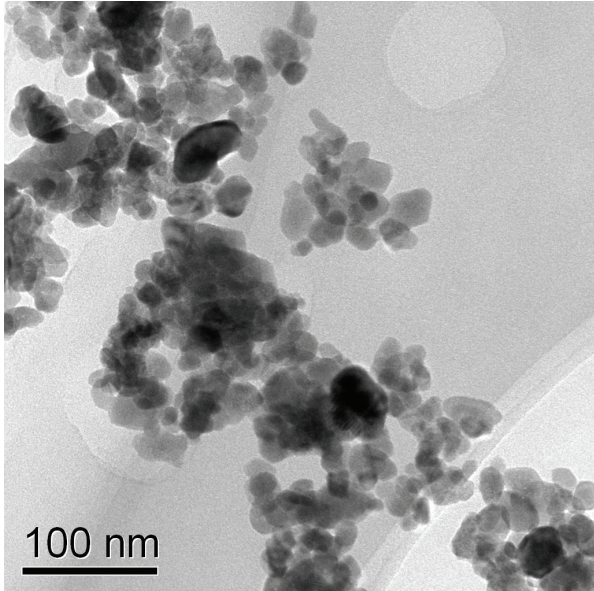

(a)

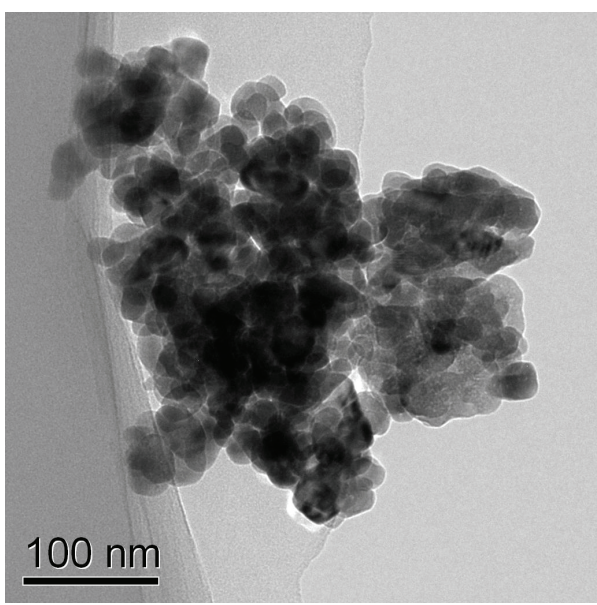

(c)

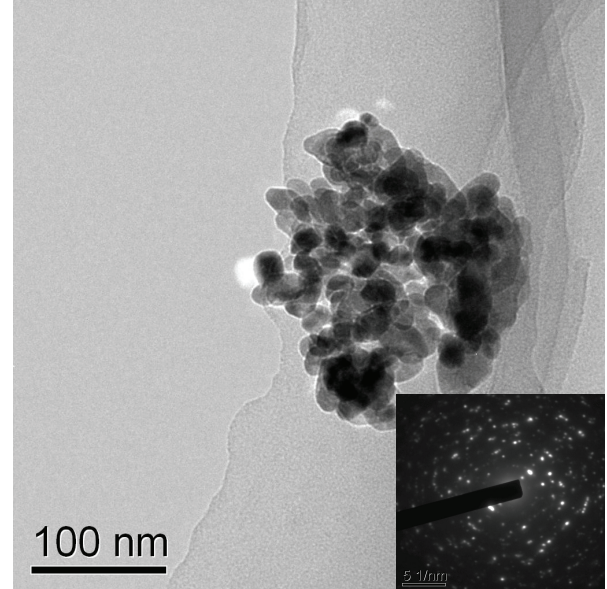

(b)

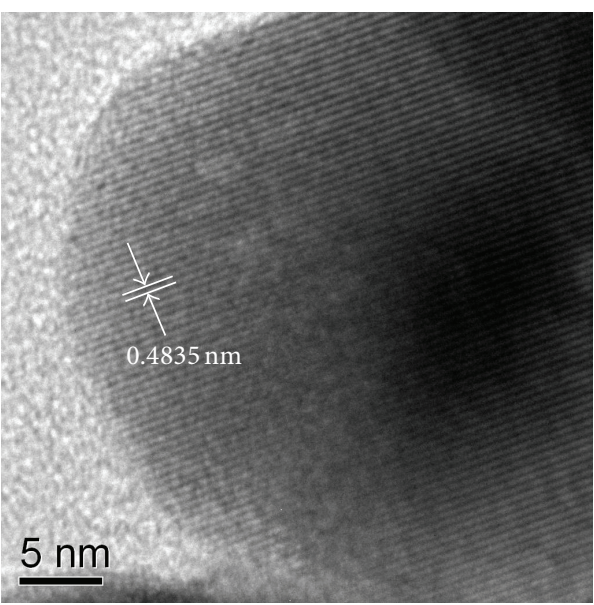

(d)

FIGURE 3: TEM images of the as-prepared $\mathrm{CaWO}_{4}$ samples synthesized at $120^{\circ} \mathrm{C}$ for different reaction times: (a) $5 \mathrm{~min}$, (b) $10 \mathrm{~min}$, and (c) 15 min. (d) A typical higher magnification TEM image of the obtained $\mathrm{CaWO}_{4}$ crystals.

$0.4835 \mathrm{~nm}$ and in consonance with the (101) face. Thus, it indicates that $\mathrm{CaWO}_{4}$ nanocrystals were synthesized by directional connection and self-assembly.

At room temperature, $\mathrm{PL}$ property of the $\mathrm{CaWO}_{4}$ nanoparticles was initially studied. Figure 4 shows the representative PL spectrum of the $\mathrm{CaWO}_{4}$ nanoparticles synthesized at $120^{\circ} \mathrm{C}$ for $5 \mathrm{~min}$ (a), $10 \mathrm{~min}$ (b), and $15 \mathrm{~min}$ (c), respectively. With the excited wavelength at $250 \mathrm{~nm}$, the corresponding broad emission peak at $420 \mathrm{~nm}$ was observed. Further studies on PL property of the as-prepared $\mathrm{CaWO}_{4}$ nanoparticles were in progress. With the increasing of the reaction time, the emission peak value increases constantly, which has the same change with morphology and crystallinity. These results strongly indicate that the PL properties of $\mathrm{CaWO}_{4}$ are sensitive to the degree of structural orderdisorder (crystallinity) and the relatively weak variations in the atomic arrangements which was basically in agreement with the analysis of Orhan et al. [21]. In general, the possible reasons are associated with the charge-transfer transitions within the $\left[\mathrm{WO}_{4}\right]^{2-}$ complexes [26-29] or due to the vacancies as $\left[\mathrm{WO}_{3} \cdot V_{\mathrm{O}}^{z}\right][30]$ and $\left[\mathrm{CaO}_{7} \cdot V_{\mathrm{O}}^{z}\right][31]$.

\section{Conclusions}

$\mathrm{CaWO}_{4}$ nanocrystals have been successfully prepared by microwave-assisted method at a low reaction temperature of $120^{\circ} \mathrm{C}$ with different time. Experimental results indicated that the crystallinity of as-synthesized $\mathrm{CaWO}_{4}$ was affected by the reaction time. With the prolonging of the reaction time, the crystallinity of the sample got higher, and the average diameter of particles got bigger. The $\mathrm{CaWO}_{4}$ nanocrystal obtained by this preparation method has favourable luminance, which receives emissive wavelength at $420 \mathrm{~nm}$ with the excitation wavelength at $250 \mathrm{~nm}$. It indicated that the kernel became bigger, the crystallinity was higher, and the intensity of fluorescence changed to become stronger as time went on.

\section{Acknowledgments}

The authors acknowledge with thanks the financial support of Provincial Natural Science Foundation of Hunan, China, (13JJ6041) and the National Natural Science Foundation of China (21343008). 


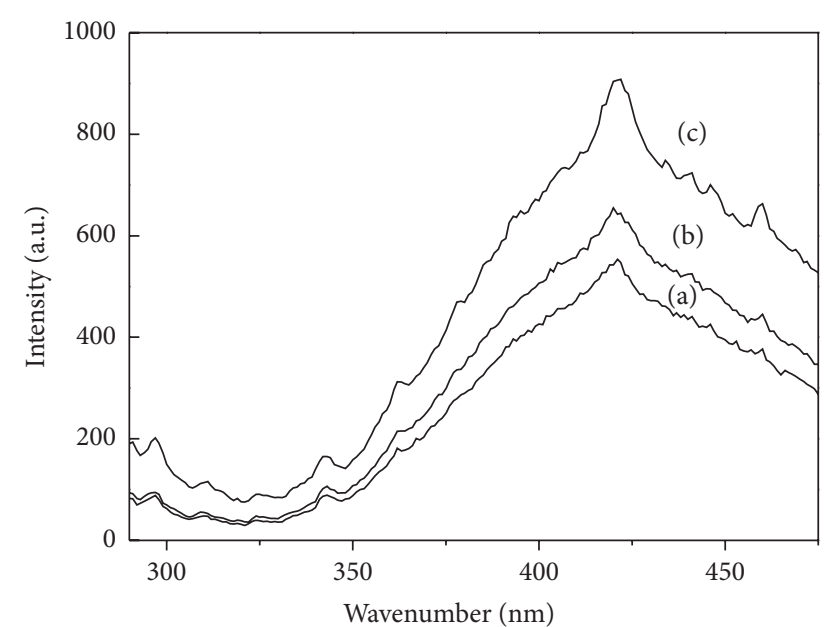

FIgURE 4: PL spectra of the $\mathrm{CaWO}_{4}$ nanoparticles synthesized at $120^{\circ} \mathrm{C}$ for (a) $5 \mathrm{~min}$, (b) $10 \mathrm{~min}$, and (c) $15 \mathrm{~min}$.

\section{Conflict of Interests}

The authors declared that they have no conflict of interests to this work.

\section{References}

[1] Y. Wang, J. Ma, J. Tao et al., "Synthesis of $\mathrm{CaWO}_{4}$ nanoparticles by a molten salt method," Materials Letters, vol. 60, no. 2, pp. 291-293, 2006.

[2] Y. Cui, Q. Wei, H. Park, and C. M. Lieber, "Nanowire nanosensors for highly sensitive and selective detection of biological and chemical species," Science, vol. 293, no. 5533, pp. 1289-1292, 2001.

[3] M. H. Huang, S. Mao, H. Feick et al., "Room-temperature ultraviolet nanowire nanolasers," Science, vol. 292, no. 5523, pp. 1897-1899, 2001.

[4] J. Hu, T. W. Odom, and C. M. Lieber, "Chemistry and physics in one dimension: synthesis and properties of nanowires and nanotubes," Accounts of Chemical Research, vol. 32, no. 5, pp. 435-445, 1999.

[5] H.-W. Liao, Y.-F. Wang, X.-M. Liu, Y.-D. Li, and Y.-T. Qian, "Hydrothermal preparation and characterization of luminescent $\mathrm{CdWO}_{4}$ nanorods," Chemistry of Materials, vol. 12, no. 10, pp. 2819-2821, 2000.

[6] G. Blasse and W. J. Schipper, "Low-temperature photoluminescence of strontium and barium tungstate," Physica Status Solidi (A), vol. 25, pp. K163-K165, 1974.

[7] M. Martini, F. Meinardi, G. Spinolo, A. Vedda, M. Nikl, and Y. Usuki, "Shallow traps in $\mathrm{PbWO}_{4}$ studied by wavelengthresolved thermally stimulated luminescence," Physical Review $B$, vol. 60, no. 7, pp. 4653-4658, 1999.

[8] M. A. M. A. Maurera, A. G. Souza, L. E. B. Soledade et al., "Microstructural and optical characterization of $\mathrm{CaWO}_{4}$ and $\mathrm{SrWO}_{4}$ thin films prepared by a chemical solution method," Materials Letters, vol. 58, no. 5, pp. 727-732, 2004.

[9] M. Itoh and M. Fujita, "Optical properties of scheelite and raspite $\mathrm{PbWO}_{4}$ crystals," Physical Review B, vol. 62, no. 19, pp. $12825-12830,2000$.
[10] M. J. Treadaway and R. C. Powell, "Energy transfer in samarium-doped calcium tungstate crystals," Physical Review B, vol. 11, no. 2, pp. 862-874, 1975.

[11] S. Oishi and M. Hirao, "Growth of $\mathrm{CaWO}_{4}$ whiskers from $\mathrm{KCl}$ flux," Journal of Materials Science Letters, vol. 8, no. 12, pp. 13971398, 1989.

[12] M. Kobayashi, M. Ishii, Y. Usuki, and H. Yahagi, "Scintillation characteristics of $\mathrm{PbWO}_{4}$ single crystals at room temperature," Nuclear Instruments and Methods in Physics Research A, vol. 333, no. 2-3, pp. 429-433, 1993.

[13] G. Blasse and L. H. Brixner, "Ultraviolet emission from $\mathrm{ABO}_{4}{ }^{-}$ type niobates, tantalates and tungstates," Chemical Physics Letters, vol. 173, no. 5-6, pp. 409-411, 1990.

[14] M. Sadegh, A. Badiei, A. Abbasi, H. Goldooz, and G. Mohammadi Ziarani, "Preparation of $\mathrm{CaWO}_{4}: \mathrm{Ln}^{3+} @ \mathrm{SiO}_{2}(\mathrm{Ln}=\mathrm{Tb}, \mathrm{Dy}$ and $\mathrm{Ho}$ ) nanoparticles by a combustion reaction and their optical properties," Journal of Luminescence, vol. 130, no. 11, pp. 2072-2075, 2010.

[15] J. H. Ryu, J.-W. Yoon, C. S. Lim, W.-C. Oh, and K. B. Shim, "Microwave-assisted synthesis of nanocrystalline $\mathrm{MWO}_{4}(\mathrm{M}$ : $\mathrm{Ca}, \mathrm{Ni}$ ) via water-based citrate complex precursor," Ceramics International, vol. 31, no. 6, pp. 883-888, 2005.

[16] Q. Xiao, Q. Zhou, and M. Li, "Synthesis and photoluminescence properties of $\mathrm{Sm}^{3+}$-doped $\mathrm{CaWO}_{4}$ nanoparticles," Journal of Luminescence, vol. 130, no. 6, pp. 1092-1094, 2010.

[17] J. k. Liu, Q. S. Wu, and Y. P. Ding, "Morphologies-controlled synthesis of $\mathrm{CaWO}_{4}$ crystals by a novel supramolecular template method," Journal of Crystal Growth, vol. 279, no. 3-4, pp. 410414, 2005.

[18] E. F. Paski and M. W. Blades, "Analysis of inorganic powders by time-wavelength resolved luminescence spectroscopy," Analytical Chemistry, vol. 60, no. 11, pp. 1224-1230, 1988.

[19] L. Gracia, V. M. Longo, L. S. Cavalcante et al., "Presence of excited electronic state in $\mathrm{CaWO}_{4}$ crystals provoked by a tetrahedral distortion: an experimental and theoretical investigation," Journal of Applied Physics, vol. 110, no. 4, Article ID 043501, 2011.

[20] V. M. Longo, L. Gracia, D. G. Stroppa et al., "A joint experimental and theoretical study on the nanomorphology of $\mathrm{CaWO}_{4}$ crystals," Journal of Physical Chemistry C, vol. 115, no. 41, pp. 20113-20119, 2011.

[21] E. Orhan, M. Anicete-Santos, M. A. M. A. Maurera et al., "Towards an insight on the photoluminescence of disordered $\mathrm{CaWO}_{4}$ from a joint experimental and theoretical analysis," Journal of Solid State Chemistry, vol. 178, no. 4, pp. 1284-1291, 2005.

[22] L. S. Cavalcante, V. M. Longo, J. C. Sczancoski et al., "Electronic structure, growth mechanism and photoluminescence of $\mathrm{CaWO}_{4}$ crystals," CrystEngComm, vol. 14, no. 3, pp. 853-868, 2012.

[23] Y. Wang, J. Ma, J. Tao et al., "Synthesis of $\mathrm{CaWO}_{4}$ nanoparticles by a molten salt method," Materials Letters, vol. 60, no. 2, pp. 291-293, 2006.

[24] A. Kato, S. Oishi, T. Shishido, M. Yamazaki, and S. Iida, "Evaluation of stoichiometric rare-earth molybdate and tungstate compounds as laser materials," Journal of Physics and Chemistry of Solids, vol. 66, no. 11, pp. 2079-2081, 2005.

[25] F. Lei and B. Yan, "Hydrothermal synthesis and luminescence of $\mathrm{CaMO}_{4}: \mathrm{RE}^{3+}(\mathrm{M}=\mathrm{W}, \mathrm{Mo}$; $\mathrm{RE}=\mathrm{Eu}, \mathrm{Tb})$ submicro-phosphors," Journal of Solid State Chemistry, vol. 181, no. 4, pp. 855-862, 2008. 
[26] D. Chen, G. Shen, K. Tang, H. Zheng, and Y. Qian, "Lowtemperature synthesis of metal tungstates nanocrystallites in ethylene glycol," Materials Research Bulletin, vol. 38, no. 14, pp. 1783-1789, 2003.

[27] S.-J. Chen, J. Li, X.-T. Chen, J.-M. Hong, Z. Xue, and X.-Z. You, "Solvothermal synthesis and characterization of crystalline $\mathrm{CaWO}_{4}$ nanoparticles," Journal of Crystal Growth, vol. 253, no. 1-4, pp. 361-365, 2003.

[28] R. Zhai, H. Wang, H. Yan, and M. Yoshimura, "Preparation of crystalline $\mathrm{CaWO}_{4}$ thin films by chemical bath deposition," Journal of Crystal Growth, vol. 289, no. 2, pp. 647-651, 2006.

[29] Z. L. Wang, G. Z. Li, and Z. W. Quan, "Nanostructured $\mathrm{CaWO}_{4}$, $\mathrm{CaWO}_{4} /: \mathrm{Pb}^{2+}$ and $\mathrm{CaWO}_{4}: \mathrm{Tb}^{3+}$ particles: polyol-mediated synthesis and luminescent properties," Journal of Nanoscience and Nanotechnology, vol. 7, pp. 602-609, 2007.

[30] T. Liu, J. Chen, and F. Yan, "Optical polarized properties related to the oxygen vacancy in the $\mathrm{CaMoO}_{4}$ crystal," Journal of Luminescence, vol. 129, no. 2, pp. 101-104, 2009.

[31] A. B. Campos, A. Z. Simões, E. Longo et al., "Mechanisms behind blue, green, and red photoluminescence emissions in $\mathrm{CaWO}_{4}$ and $\mathrm{CaMoO}_{4}$ powders," Applied Physics Letters, vol. 91, no. 5, Article ID 051923, 2007. 

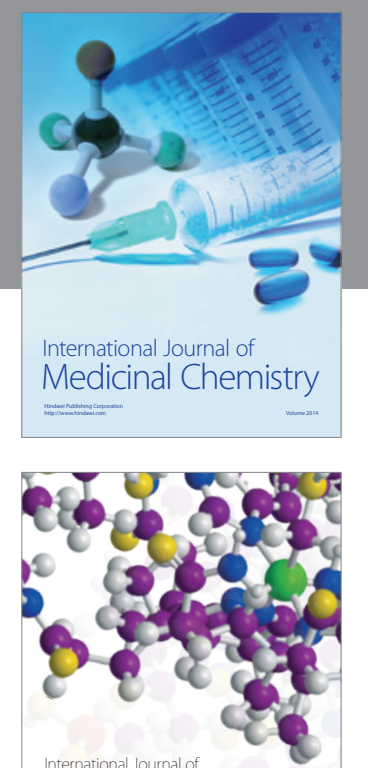

\section{Carbohydrate} Chemistry

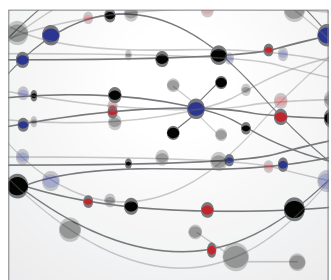

The Scientific World Journal
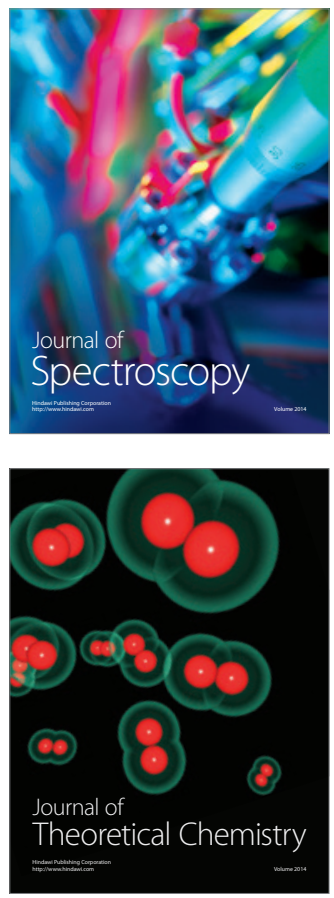
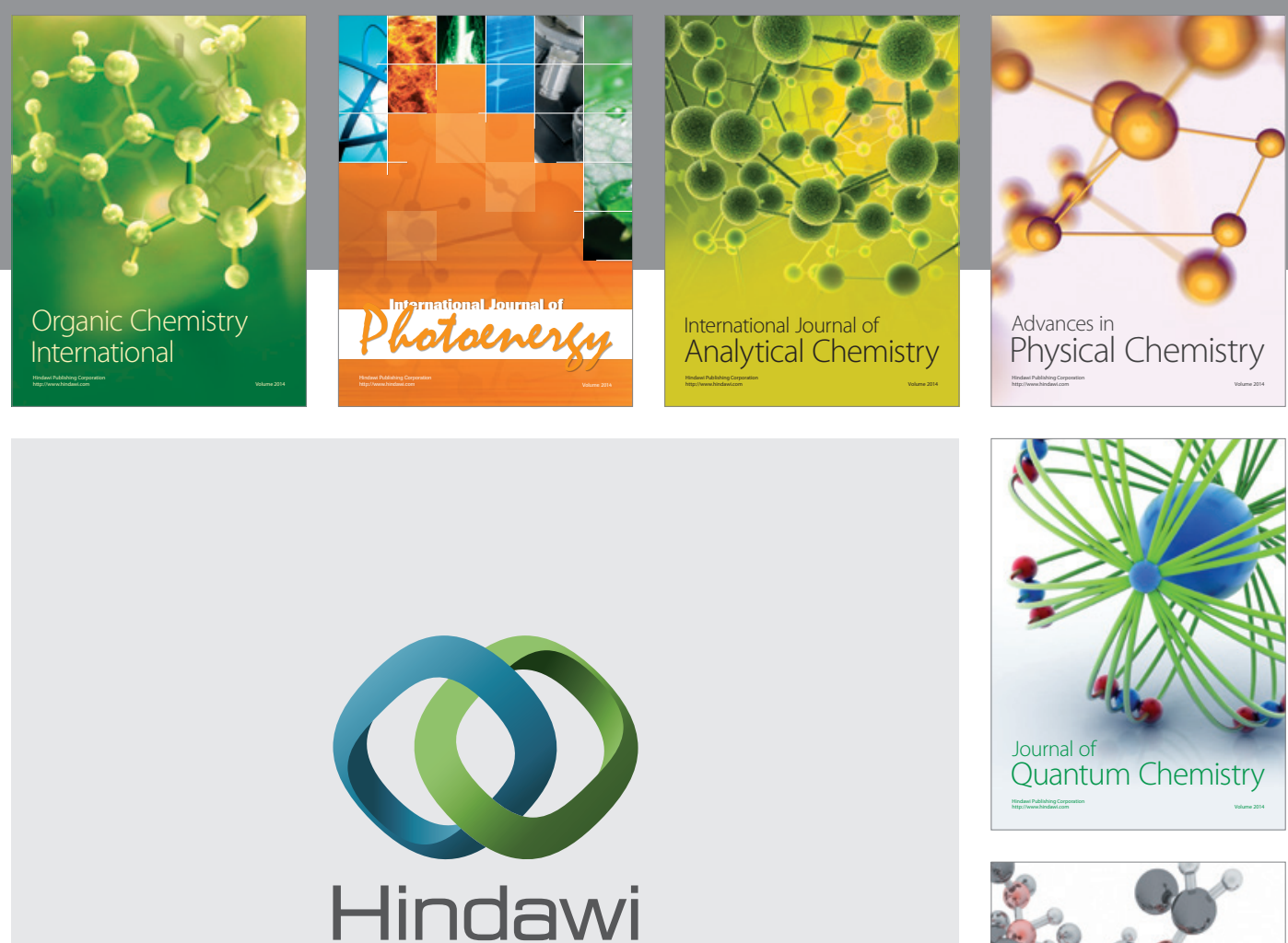

Submit your manuscripts at

http://www.hindawi.com

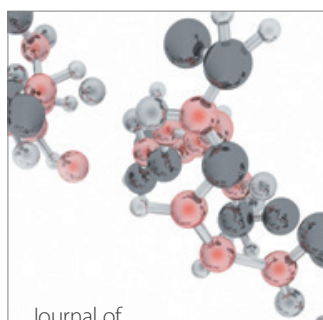

Analytical Methods

in Chemistry

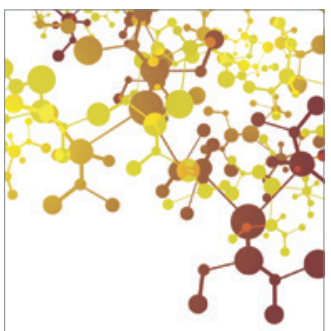

Journal of

Applied Chemistry

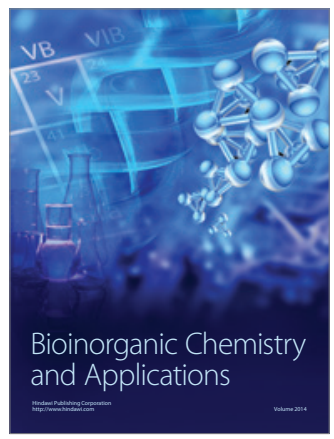

Inorganic Chemistry
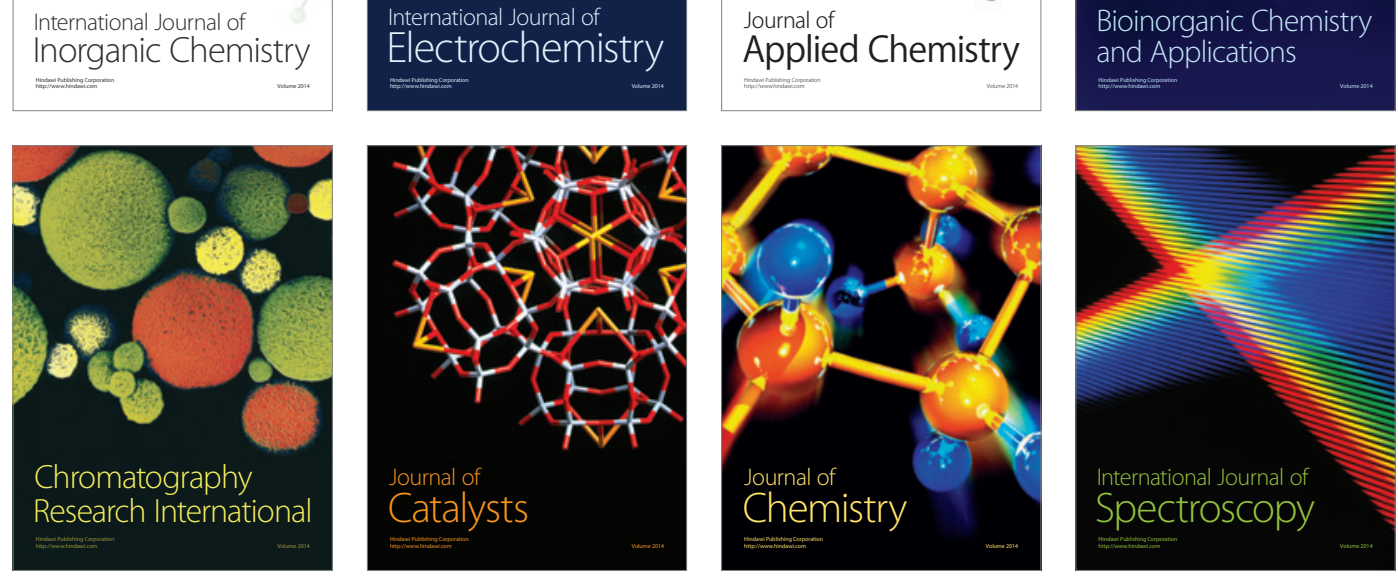